Orbis Tertius, vol. XXIV, $\mathrm{n}^{\circ}$ 30, e138, noviembre 2019-abril 2020. ISSN 1851-7811

Universidad Nacional de La Plata

Facultad de Humanidades y Ciencias de la Educación

Centro de Estudios deTeoría y Crítica Literaria

\title{
Carlos Abraham, La editorial Acme: el sabor de la aventura. Temperley, Tren en Movimiento, 2017, Sentidos del libro, 256 páginas
}

Luego de La editorial Tor: medio siglo de libros populares (Abraham, 2012) —reseñado oportunamente en un número anterior de Orbis Tertius (Mascioto, 2014)—, en 2017 Carlos Abraham publica un libro que integra el mismo proyecto de estudio de un entramado de editoriales significativas en el desarrollo de la industria editorial en nuestro país durante el siglo XX. En esta ocasión, se trata de un trabajo centrado en la historia y las publicaciones de la Editorial Acme, desde sus inicios en 1927 (aunque su etapa como casa editorial propiamente dicha comience recién en 1942) hasta su cierre definitivo a fines de 2012.

Además de una breve introducción en que se explicita el objetivo del estudio, podemos identificar tres grandes partes que componen el texto: en primer lugar, un capítulo dedicado a discutir algunos aspectos teóricos e históricos en relación a la denominada literatura de masas; en segundo término, un capítulo centrado en la historia de la Editorial Acme y las acciones de los agentes más significativos que incidieron en su creación y desarrollo; y, por último, cinco capítulos - de diversa extensión - abocados a una tarea descriptiva de las distintas colecciones de la editorial: Colecciones de literatura general; Colecciones de literatura de masas — capítulo que resulta fundamental, debido al nivel de circulación que adquirieron algunas de estas colecciones, como Robin Hood o Rastros-; Colecciones de literatura infantil; Libros técnicos y cientificos y Colecciones de historieta. El texto se cierra con un apartado de palabras finales, a las que siguen dos apéndices con listados de títulos de las colecciones Centauro y Robin Hood (y, en medio del libro, en páginas sin numeración, hallamos una muestra de algunas tapas de las publicaciones de las distintas colecciones de la editorial, entre las que resaltan, desde luego, las tapas amarillas de la serie Robin Hood).

Desde las primeras páginas de la introducción, Abraham establece de manera clara su enfoque de una historia y sociología literarias con énfasis en las actividades de edición:

El rol del editor era aún más relevante en el ámbito de la literatura de masas, donde la producción textual no surgía de la decisión autoral, sino de los requisitos comerciales planteados por la empresa con el fin de satisfacer al mercado. Es decir, no provenía de la pura intencionalidad artística sino de una demanda del lectorado que, al ser percibida por el editor, era satisfecha con la oferta de un producto cultural hecho a medida (p. 8).

El autor, por cierto, aclara que, más allá del carácter acomodaticio al público por parte de los editores, asimismo "existía una construcción del mercado lector" (p. 8). En el caso particular de Acme, Abraham sostiene que

[...] la principal característica distintiva fue la edición de literatura masiva de calidad. A diferencia de Tor o Molino, abundaba en libros de tapa dura con sobrecubierta, era relativamente estricta en la selección de textos, empleaba traducciones propias, tenía un plantel de ilustradores reclutados entre lo más prestigioso del ámbito artístico nacional y publicaba el texto completo de las obras [...] o, cuando debía abreviarlas, no omitía el reconocimiento de dicha circunstancia. (p. 9)

En la primera parte del libro, en el capítulo en torno al concepto de literatura de masas, Abraham parte de una clasificación que, más allá de posibles debates, no deja de mostrar su utilidad. Plantea la existencia de una "alta" y una "baja" literaturas (al menos durante una parte significativa del siglo XX); dentro de esta última, identifica lo que denomina como literaturas marginales y, a su vez, dentro de estas, distingue entre 
literaturas marginales programáticas y no programáticas. Al interior de esta postrera clasificación, ubica tanto a la literatura folklórica como a la de masas - y describe, a grandes rasgos, características distintivas de ambas - En las demás secciones del mismo capítulo, se dedica a repasar otros aspectos: la recepción crítica de la literatura de masas, los géneros y formatos de la misma, sus primeros editores en la Argentina, así como una síntesis de su evolución - a nivel nacional e internacional - desde el siglo XIX hasta su declive durante la segunda mitad del siglo XX.

La segunda parte del libro, es decir, el capítulo bajo el título de La editorial Acme, presenta un repaso por la historia de la misma, con énfasis en las actividades de sus directivos y agentes principales: Modesto Edarra y Amadeo Blois. A ellos se suma, por ejemplo, la importancia de Vera Lapegna, cuya trayectoria en la empresa comienza por el desempeño de tareas administrativas para, posteriormente, sumar responsabilidades en la selección de textos y asignación de trabajos a diferentes artistas - y también resulta una entrevistada e informante clave en la investigación de Abraham. En este capítulo se hace hincapié tanto en la apoliticidad de Acme - que, según Abraham, se aproxima a Tor en el sentido de que estas empresas "no tuvieron una ideología política o un proyecto social tras sus publicaciones, a diferencia de la contemporánea Claridad o del posterior Centro Editor de América Latina" (p. 55) - como en su carácter eminentemente comercial, que se percibía concretamente en la continuidad - o no- de las distintas colecciones según el número de ventas que generaban.

En la tercera parte del libro, en los capítulos centrados en las distintas colecciones de la editorial, Abraham incorpora reseñas biográficas de distintos colaboradores: traductores, ilustradores y escritores (ya fuera que figuraran con su firma original o con pseudónimo), algunos de los cuales incluso desempeñaron distintas tareas, como el caso de Alfredo Grassi, que escribía y traducía - y de quien se puede conocer su vida y obra de manera más detallada en el libro Una vida entre cuadritos y celuloide (Grassi, 2015). Asimismo, Abraham incluye referencias a figuras totalmente desconocidas para el mundo de las letras consagradas, como Rodolfo Bellani, de quien podemos traer a cuenta el siguiente extracto de vida:

Fue uno de los más prolíficos escritores argentinos, con cerca de cuatrocientos títulos. También uno de los más desconocidos, debido a que se consagró a géneros poco prestigiosos como las novelas de vaqueros y de piratas, al uso de pseudónimos que disminuyeron su visibilidad autorial y a su escaso contacto con grupos literarios (p. 115).

Por cierto, todos estos agentes tomados de manera conjunta, en sus distintas funciones, antes que aproximarnos a un enfoque bourdiano sobre el arte y la literatura (centrada en las disputas de los agentes por posicionarse y legitimarse en un campo cultural), nos permiten pensar en un enfoque más bien cercano al de Howard Becker (2008) y, en tal sentido, podríamos concebir los más de mil quinientos títulos de la editorial como una creación derivada de una colaboración colectiva de largo aliento y nombres cambiantes.

La lectura del trabajo de Abraham suscita una reacción de inevitable encomio frente a la ardua empresa, tomada a título individual, de recopilar un ingente material bibliográfico, hacer entrevistas con informantes claves y organizar el caudal informativo en una muy prolija presentación, que facilita el acceso del lector a un panorama de la historia y las colecciones de Acme. El propio autor reconoce esta situación, cuando afirma: "la inexistencia de bibliografía previa ha llevado a que mi libro sea en su totalidad trabajo de campo" (p. 9).

Sin embargo, en las primeras páginas del texto hay una suerte de ajuste de cuentas con la academia, a la que Abraham cuestiona por reproducir una coyuntura en la que "los papers universitarios se limitan a citarse entre sí, sin molestarse en realizar investigación propia” (p. 9). La invectiva contra el ámbito académico, quizá dotada de cierto resentimiento innecesario, prosigue unas páginas después, cuando Abraham habla de los productos hiperespecializados de tesis, tesinas y monografías de grado y posgrado, que suelen "mostrar un notorio predominio de textos teóricos o críticos, pero sólo una o dos obras literarias pertenecientes a los géneros estudiados" (p. 20). Si bien este comentario tiene una base de razonabilidad, resulta un poco llamativo, visto el nivel de conocimiento demostrado por el autor, su indiferencia respecto al surgimiento, en los últimos años, de distintos focos de estudio en el país en torno a los denominados estudios sobre el libro 
y la edición -algunas de cuyas figuras más visibles son, no tesistas de grado y posgrado, sino investigadores formados y de reconocida trayectoria, como Gustavo Sorá en Córdoba, Alejandro Dujovne en Buenos Aires y José Luis de Diego en La Plata, localidad de la que también proviene el propio Abraham.

El aporte de Abraham, por supuesto, se torna una lectura obligada no solo en la arena de los estudios sobre edición, sino también en los estudios literarios sobre literatura argentina o sobre géneros narrativos -el libro cuenta con numerosos datos interesantes de bibliografía y escritores para quienes, por ejemplo, nos abocamos a los estudios sobre literatura policial. Por cierto, el énfasis de Abraham en la historia concreta de la editorial y en las decisiones económicas de la misma, en tanto se configura como una empresa guiada por una lógica de rentabilidad, nos devuelve asimismo a una forma de ver la literatura en su aspecto mercantilizado, sin que esto suponga algún tipo de valoración negativa - tal como sucede en cierto tipo de concepciones que entienden a la literatura como una práctica individual de sujetos excelsos en que se pone en juego un reconocimiento simbólico.De hecho, la lógica comercial que orientaba las actividades de la empresa ha dejado huellas en el ámbito cultural nacional e internacional, tal como sostiene Abraham en el cierre del primer capítulo del libro, que aquí podemos tomar como palabras finales de nuestra reseña:

Acme fue una editorial clave en el ámbito de la literatura argentina de masas. Una suerte de hermana menor de Tor, aunque más respetada que ésta. Sus diversas colecciones son esenciales para entender tanto la literatura como el mercado editorial de nuestro país. Una de ellas, Rastros, estuvo entre las más leídas de su tiempo e impuso el policial negro en España y Latinoamérica. Otra, Centauro, fue decisiva en la implantación del formato de libro de bolsillo. Otra, Suplemento de Rastros, impuso definitivamente la literatura de vaqueros en el ámbito de la lengua española. Pero, sin duda, la colección que perdura indeleble en la memoria de todo lector argentino es Robin Hood. Esos entrañables libros amarillos, cargados de aventura y de exotismo, en los cuales las fascinantes tapas invitaban a soñar incluso antes de abrir las páginas. (2017: 69) 